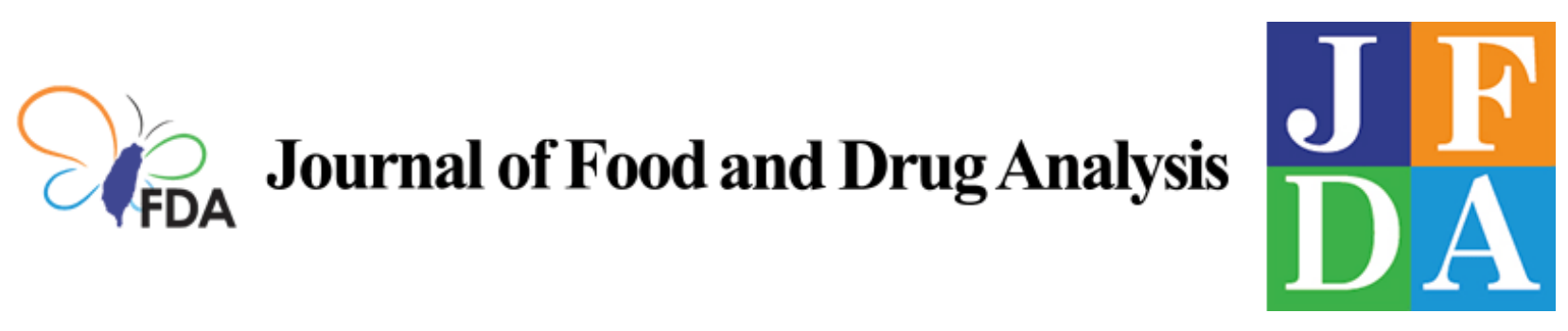

Volume 29 | Issue 4

Article 9

2021

\title{
Pharmacokinetics of panduratin a following oral administration of a Boesenbergia pandurata extract to rats
}

Follow this and additional works at: https://www.jfda-online.com/journal

Part of the Food Science Commons, Medicinal Chemistry and Pharmaceutics Commons, Pharmacology Commons, and the Toxicology Commons

(c) (i) (9)

This work is licensed under a Creative Commons Attribution-Noncommercial-No Derivative Works 4.0 License.

\section{Recommended Citation}

Won, Jihyun; Noh, Keumhan; Hwang, Jae-Kwan; Shin, Beom Soo; and Kang, Wonku (2021)

"Pharmacokinetics of panduratin a following oral administration of a Boesenbergia pandurata extract to rats," Journal of Food and Drug Analysis: Vol. 29 : Iss. 4 , Article 9.

Available at: https://doi.org/10.38212/2224-6614.3382

This Original Article is brought to you for free and open access by Journal of Food and Drug Analysis. It has been accepted for inclusion in Journal of Food and Drug Analysis by an authorized editor of Journal of Food and Drug Analysis. 


\title{
Pharmacokinetics of panduratin A following oral administration of a Boesenbergia pandurata extract to rats
}

\author{
Jihyun Won ${ }^{\text {, }}$ Keumhan Noh ${ }^{\text {, }}$, Jae-Kwan Hwang ${ }^{\text {c, }}$, \\ Beom Soo Shin ${ }^{\mathrm{d}, * *}$, Wonku Kang ${ }^{\mathrm{a}, * * *}$ \\ ${ }^{a}$ College of Pharmacy, Chung-Ang University, Seoul 06974, South Korea \\ ${ }^{\mathrm{b}}$ Deapartment of Pharmaceutical Sciences, Leslie Dan Faculty of Pharmacy, University of Toronto, Toronto, ON M55 3M2, Canada \\ ${ }^{\mathrm{c}}$ Department of Biotechnology, College of Life Science and Biotechnology, Yonsei University, Seoul 03722, South Korea \\ d School of Pharmacy, Sungkyunkwan University, Suwon 16419, South Korea
}

\begin{abstract}
Boesenbergia pandurata and its major active ingredient, panduratin A (PAN), exhibit antibacterial, anti-oxidant, antiinflammatory, and anti-obesity effects. We explored the time course of the plasma and tissue (in the major organs, gums and skin) concentrations of PAN after oral administration of a B. pandurata extract to rats. Model-dependent analysis was used to quantify the skin distribution of PAN after systemic exposure. The PAN level peaked at $1.12 \pm 0.22 \mu \mathrm{g} / \mathrm{mL}$ after $3 \mathrm{~h}$, and then biexponentially decayed with a terminal half-life of $9 \mathrm{~h}$. The mean clearance $(\mathrm{Cl} / \mathrm{F}) \mathrm{was} 2.33 \pm 0.68 \mathrm{~L} / \mathrm{h} /$ $\mathrm{kg}$. The PAN levels in organs were in the following order (highest first): skin, lung, heart, gum, liver, spleen, kidney, and brain. For the first time, the time course of PAN levels in plasma and organs was investigated after oral administration of a BPE. This study helps to explain the pharmacological activities of PAN in the skin and gums. The pharmacokinetic model provided data in the plasma and skin concentrations of PAN, which are of fundamental importance to evaluate its efficacy.
\end{abstract}

Keywords: BPE, Panduratin A, Pharmacokinetic modeling, Plasma, Skin

\section{Introduction}

$B$ oesenbergia pandurata Roxb. is a tropical plant of the Zingiberaceae family commonly referred to as fingerroot. Panduratin A (PAN; Fig. 1), a chalcone, is the major bioactive agent of $B$. pandurata [1] and has antibacterial, anti-inflammatory, antioxidant, and anti-obesity effects [2-4]. Previous studies of the anti-inflammatory effects of PAN used lipopolysaccharide (LPS)-stimulated RAW264.7 cells $[5,6]$. Both B. pandurata extract (BPE) and PAN exhibited anti-periodontitis activity in LPS-treated animal models [7,8]. In 2012, BPE was approved as a health/functional food by the Ministry of Food and Drug Safety of Korea (No. 2012-36), and was indicated for use as a dietary supplement and in skin moisturizers and products protecting the skin against ultraviolet (UV) light exposure [9-12].

In previous in vivo work, BPE was administered at 50 and $200 \mathrm{mg} / \mathrm{kg}$ to investigate its anti-inflammatory effects in a lipopolysaccharide-induced periodontitis and alveolar bone loss rat model [8]. BPE significantly increased the mRNA and protein expression levels of nuclear factor kappa B (NF- $\kappa \mathrm{B})$, interleukin-1b, matrix metalloproteinase (MMP)-2, and MMP-8. BPE also exerted inhibitory effects on the expression of nuclear factor of activated $\mathrm{T}$ cells, cytoplasmic 1, c-Fos, and osteoclastogenesis-related enzymes, including cathepsin $\mathrm{K}$ and tartrate-resistant acid phosphatase (TRAP). BPE upregulated

Received 13 April 2021; revised 30 June 2021; accepted 27 August 2021.

Available online 15 December 2021.

* Corresponding author at:

** Corresponding author at:

*** Corresponding author at:

E-mail addresses: jkhwang@yonsei.ac.kr (J.-K. Hwang), bsshin@skku.edu (B.S. Shin), wkang@cau.ac.kr (W. Kang). 

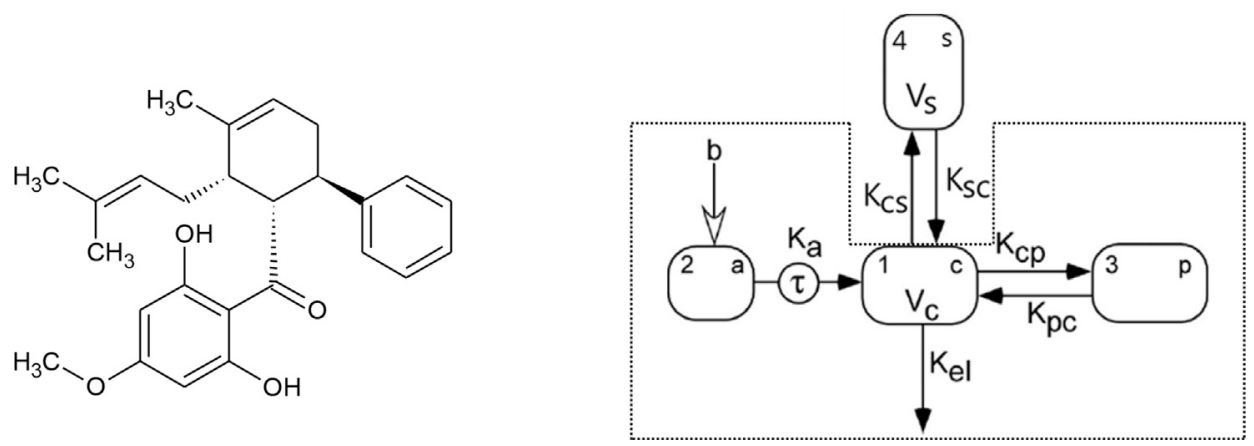

Fig. 1. Chemical structure of pandurantin A (left) and pharmacokinetic model (right) of the time courses of plasma (dotted box) and skin panduratin A levels following oral administration of $200 \mathrm{mg} / \mathrm{kg}$ BPE to rats; $b$, bolus administration into the stomach; $a$, depot compartment; $c$, central; $p$, peripheral; s, skin; $K_{a}$ absorption rate constant; $\tau$, delay parameter; $K_{\text {el }}$ elimination rate constant; $K_{i j}$, first-order rate constant from compartment $i$ to $j$; $V_{i}$ volume of compartment $i$.

osteoblastogenesis-associated markers, such as collagen type I and TRAP, and increased the ratio of osteoprotegerin to receptor activator of $\mathrm{NF}-\kappa \mathrm{B}$ ligand.

In a high-fat-induced obesity mouse model, BPE was given at $200 \mathrm{mg} / \mathrm{kg}$ for 8 weeks [13]. BPE reduced body weight in the absence of alterations in food intake and serum levels of total cholesterol, low-density lipoprotein cholesterol, and triglycerides, which might be attributed to activation of AMP-activated protein kinase signalling and regulation of the expression of lipid metabolismrelated proteins.

Although the pharmacological activities of both plant extracts and PAN have been intensively studied, the pharmacokinetics of PAN in rats have been reported only by our group [14]. The mean terminal phase half-life and clearance were $3.6 \mathrm{~h}$ and $3.7 \mathrm{~L} / \mathrm{h} / \mathrm{kg}$, respectively, following oral administration. Systemic exposure levels (including tissue distribution) are required when studying the pharmacodynamic actions of the active ingredients of plants.

In this work, we explored the time courses of plasma and organ (lung, heart, spleen, liver, kidney, and brain, including skin and gum) PAN levels following oral administration of BPE at $200 \mathrm{mg} / \mathrm{kg}$ in rats. The content of PAN in BPE was $8 \%$, and the BPE dose $(200 \mathrm{mg} / \mathrm{kg})$ was equivalent to $16 \mathrm{mg} / \mathrm{kg}$ of PAN [8]; 50 and $100 \mathrm{mg} / \mathrm{kg}$ of BPE were also given to investigate the dose-dependency of systemic exposure to PAN. The deposition of PAN in the skin was the main focus. The time profiles of plasma and skin PAN concentrations were modelled using a compartmental modelling approach, which was applied to simulate PAN levels in skin and plasma after multiple doses of BPE.

\section{Methods}

\subsection{Materials}

The dried rhizomes of $B$. pandurata were collected in Jakarta, Indonesia, and identified by Dr. Nam-In Baek (Department of Oriental Medicinal Materials and Processing, Kyunghee University, Yongin, Korea). The BPE was obtained by following a standard operating procedure [8]. Briefly, dried rhizomes of B. pandurata (Roxb.) were ground and extracted into $95 \%(\mathrm{v} / \mathrm{v})$ ethanol for 3 days at room temperature. The filtrate was evaporated and the PAN content measured. The chromatogram and mass spectra of pandurate A are shown in Supplement 1. Ethanol was obtained from Duksan Chemicals (Kyunggi-do, South Korea). Flufenamic acid and acetonitrile were purchased from Sigma-Aldrich (St. Louis, MO, USA); PAN (purity, 97.5\%) was obtained from Natural Remedies Private Ltd. (Karnataka, India).

\subsection{Animal study}

We used 30 9-week-old male Sprague-Dawley rats $(280-300 \mathrm{~g})$. The animal room was maintained at a temperature of $23 \pm 3{ }^{\circ} \mathrm{C}$, with relative humidity of $50 \pm 10 \%(10-20$ air changes/h), and light intensity of 300 Lux under a 12-h/12-h light/dark cycle. This study was approved by the Institutional Animal Care and Use Committee (IACUC) at Chung-Ang University (approval no. 201900025). All animals were cared for in accordance with the National Institutes of Health Guide for the Care and Use of Laboratory Animals.

The rats were randomized to two groups (plasma and tissue groups) including 5 and 25 animals, respectively. BPE $(200 \mathrm{mg} / \mathrm{kg})$ was orally administered in corn oil $(1 \mathrm{~mL} / \mathrm{kg})$. Heparinized blood 
samples $(100 \mu \mathrm{L})$ were prepared at $0.5,1,1.5,2,2.5,3$, $4,5,6,8,12$ and $24 \mathrm{~h}$ after extract administration; blood was collected via the subclavian vein. After centrifugation for $10 \mathrm{~min}$ at $17,000 \mathrm{rpm}, 30-\mu \mathrm{L}$ plasma samples were stored at $-70{ }^{\circ} \mathrm{C}$ prior to analysis [14]. The tissue group rats were euthanized with isoflurane, and as much blood as possible was collected from the abdominal before harvesting the organs. Heart, lungs, liver, spleen, kidney, brain, gums, and skin were collected at 1, 3, 6, 12 and $24 \mathrm{~h}$ in five subgroups of five rats each. The tissues were homogenized in a three-fold excess of phosphate buffer solution (0.1 M, pH 7.4), and an aliquot of 30$\mu \mathrm{L}$ was analyzed.

An additional 10 rats were evenly divided into two groups to explore the dose-dependency of systemic exposure to PAN following oral administration of $\mathrm{BPE} ; 50$ and $100 \mathrm{mg} / \mathrm{kg}$ of BPE were given, and plasma PAN concentrations were monitored as described above.

\subsection{Measurement of panduratin $A$ in extract, plasma, and tissues by LC-MS/MS}

PAN concentrations were determined by highperformance liquid chromatography/tandem mass spectrometry (LC-MS/MS), as previously described [14]. PAN content in the extract was determined as follows: the extract powder was initially dissolved in dimethylsulfoxide at $1 \mathrm{mg} / \mathrm{mL}$, filtered, and further diluted with methanol; the calibration standard curve of PAN in methanol was analysed to quantify the PAN concentration in the diluted solution.

PAN and flufenamic acid (internal standard, IS) were dissolved in methanol to concentrations of $1.0 \mathrm{mg} / \mathrm{mL}$. Then, PAN solutions were serially diluted with methanol, and $10 \mu \mathrm{L}$ of diluted solution was added to $90 \mu \mathrm{L}$ of drug-free plasma and tissue homogenates to obtain calibration standard plasma samples with concentrations of 5, 10, 50, 200, 500, 1,000 , and $3,000 \mathrm{ng} / \mathrm{mL}$. Three hundred microliters of acetonitrile, including the IS $(10 \mathrm{ng} / \mathrm{mL})$, were added to the calibration standards; the mixture was then vigorously vortexed for $10 \mathrm{~s}$ and centrifuged for $10 \mathrm{~min}$ at $17,000 \mathrm{rpm}$. Five microliters of the supernatant were injected into an API $4000 \mathrm{LC} / \mathrm{MS} / \mathrm{MS}$ system (ABSCIEX, Framingham, MA, USA). Using linear regression, calibration graphs were derived from the ratio between the area under the PAN peak and the IS peak.

The compounds were separated on a reverse phase column (Atlantis T3; internal diameter, $50 \times 2.1 \mathrm{~mm}$; particle size, $3 \mu \mathrm{m}$; Waters, Milford, MA, USA) at $30^{\circ} \mathrm{C}$. The mobile phase was distilled water with $0.1 \%(\mathrm{v} / \mathrm{v})$ formic acid and acetonitrile
$(4: 6, \mathrm{v} / \mathrm{v})$. Elution was performed over $5 \mathrm{~min}$ using an HP 1260 series pump (Agilent, Wilmington, DE, USA) at a rate of $0.2 \mathrm{~mL} / \mathrm{min}$. The turbo ion spray interface in the LC-MS/MS system was operated at $4500 \mathrm{~V}$ at $450{ }^{\circ} \mathrm{C}$. The ion transitions of the precursor to the product ion were deprotonated ions $[\mathrm{M}-\mathrm{H}]^{-}$ at $\mathrm{m} / \mathrm{z} 405.2 \rightarrow 165.9$ (declustering potential, $-110 \mathrm{eV}$; collision energy, $-36 \mathrm{eV}$ ) for panduratin $\mathrm{A}$ and $280.1 \rightarrow 236.0$ (declustering potential, $-75 \mathrm{eV}$; collision energy, $-24 \mathrm{eV}$ ) for flufenamic acid [14]. Quantification was performed by selective reaction monitoring of deprotonated precursor ions and related product ions using the ratio of the area under the peak for each solution. All analytical data were processed using Analyst software (ver. 1.5.2; Applied Biosystems, Foster City, CA, USA).

Ninety microliters of the IS solution was added to $30 \mu \mathrm{L}$ of a biological sample, followed by application of the same procedure described above for the calibration standards. Recovery was calculated by comparing the mean peak areas of plasma samples (low, $30 \mathrm{ng} / \mathrm{mL}$; intermediate, $500 \mathrm{ng} / \mathrm{mL}$ ) spiked before protein precipitation to those spiked after deproteination with acetonitrile. The matrix effect was evaluated based on the percentile of the mean peak areas of plasma samples spiked after pretreatment with methanol.

\subsection{Model-independent analysis}

The pharmacokinetic parameters of PAN, including the maximum concentration $\left(\mathrm{C}_{\max }\right)$ and time to $C_{\max }\left(T_{\max }\right)$, were calculated from the time course of the plasma concentration. The elimination rate constant $(\mathrm{k})$ was estimated by linear regression of the log-transformed plasma PAN concentration in the terminal phase. The trapezoidal rule was used to obtain the area under the plasma concentration-time curve $\left(A U C_{t}\right)$. The $A U C_{\text {inf }}$ was calculated by adding $C_{\text {last }} / \mathrm{k}$ to $\mathrm{AUC}_{\mathrm{t}}$ and the clearance was estimated as the dose/AUC $C_{\text {inf }}$. Data are represented as means with standard deviations.

\subsection{Model-dependent analysis}

We used a sequential approach to optimize the models of plasma and skin PAN concentrations over time; the two-compartment model included first-order elimination and absorption, and a delay term $(\tau)$ (Fig. 1 right, dotted line) [15]. In the next step, a compartment was added to model the skin PAN concentration over time. All parameters except those related to absorption $\left(K_{a}\right.$ and $\left.\tau\right)$ were estimated. 
The differential equations describing the changes in PAN level in each compartment are as follows:

$$
\frac{d x_{1}}{d t}=\mathrm{K}_{\mathrm{a}} \cdot \mathrm{x}_{2}-\left(\mathrm{K}_{\mathrm{el}}+\mathrm{K}_{\mathrm{cp}}+\mathrm{K}_{\mathrm{cs}}\right) \cdot \mathbf{x}_{1}+\mathrm{K}_{\mathrm{pc}} \cdot \mathrm{x}_{3}+\mathrm{K}_{\mathrm{sc}} \cdot \mathbf{x}_{4}
$$

$\frac{d x_{2}}{d t}=-\mathrm{K}_{\mathrm{a}} \cdot \mathrm{x}_{2}$

$\frac{d x_{3}}{d t}=\mathrm{K}_{\mathrm{cp}} \cdot \mathbf{x}_{1}-\mathrm{K}_{\mathrm{pc}} \cdot \mathrm{x}_{3}$

$\frac{d x_{4}}{d t}=\mathrm{K}_{\mathrm{cs}} \cdot \mathbf{x}_{1}-\mathrm{K}_{\mathrm{sc}} \cdot \mathbf{x}_{4}$

Equations (1)-(4) were solved numerically, and fitted to the data via maximum likelihood estimation using the ADAPT 5 software package (Biomedical Simulations Resource, Los Angeles, CA, USA) and the following error model:

$\widehat{C}\left(t_{i}\right)=C\left(t_{i}\right)+\epsilon_{\mathrm{i}}$

$\operatorname{var}\left[\epsilon_{\mathbf{i}}(\mathbf{t})\right]=\left(\sigma_{0}+\sigma_{1} \cdot \mathbf{C}\left(t_{i}\right)\right)^{2}$

where $C(t)$ is the measured concentration, and $\widehat{C}\left(t_{c}\right)=x_{1}(t) / V_{c}$ and $\widehat{C}\left(t_{s}\right)=x_{4}(t) / V_{s}$ are the model predictions of the plasma and skin PAN concentrations, respectively.

The goodness-of-fit of the model was initially evaluated by visual inspection of the overlap between the measured concentrations and predicted values. Several models were compared using the likelihood ratio test [16]. A p-value $<0.05$ was considered significant. The simplest model that adequately explained the data was selected; this model followed the parsimony principle. The goodness-of-fit and quality of the parameter

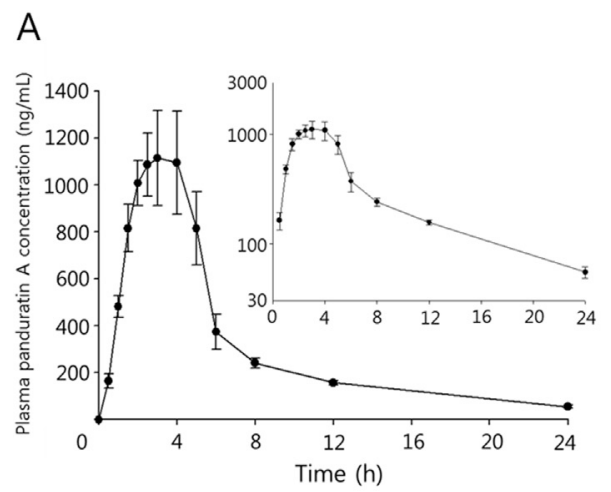

estimates were evaluated based on the coefficients of variation (CVs) of the estimates, the parameter correlation matrix, the sum of squares of the residuals, and visual examination of the residual distributions. In the first step, individual datasets were independently fitted, and mean and variance data were obtained for each pharmacokinetic parameter.

\section{Results}

3.1. Measurement of panduratin A in extract, plasma, and tissues

There was no endogenous interference in the elution times of PAN or IS in tissue homogenates. The mean calibration curve of PAN in plasma was $\mathrm{y}=0.030 \mathrm{x}+0.342\left(\mathrm{r}^{2}, 0.998\right) ;$ a good linearity was also represented in all tissues, and the representative mean calibration curve in the liver was $y=0.034 x+0.511\left(r^{2}, 0.999\right)$. The mean recovery and matrix effect using the present protein precipitation method with acetonitrile were $86 \pm 5 \%$ and $85 \pm 6 \%$ for plasma, and $89 \pm 4 \%$ and $82 \pm 7 \%$ for the liver, respectively.

\subsection{Time course of plasma and organ PAN levels following oral administration of a BPE}

The time course of the plasma PAN concentration is shown in Fig. 2A. PAN was absorbed relatively slowly, with the highest plasma concentration $(1.12 \pm 0.22 \mu \mathrm{g} / \mathrm{mL})$ seen $3 \mathrm{~h}$ after administration. The concentration rapidly decreased to $380 \pm 78 \mathrm{ng} /$ $\mathrm{mL}$ by $6 \mathrm{~h}$, and decayed more gradually thereafter (terminal half-life $=8.5 \pm 1.3 \mathrm{~h}$ ). The mean $\mathrm{AUC}_{\text {inf }}$ and clearance $(\mathrm{Cl} / \mathrm{F})$ were $7.84 \pm 1.54 \mu \mathrm{g} \mathrm{h} / \mathrm{mL}$ and $2.33 \pm 0.68 \mathrm{~L} / \mathrm{h} / \mathrm{kg}$, respectively.

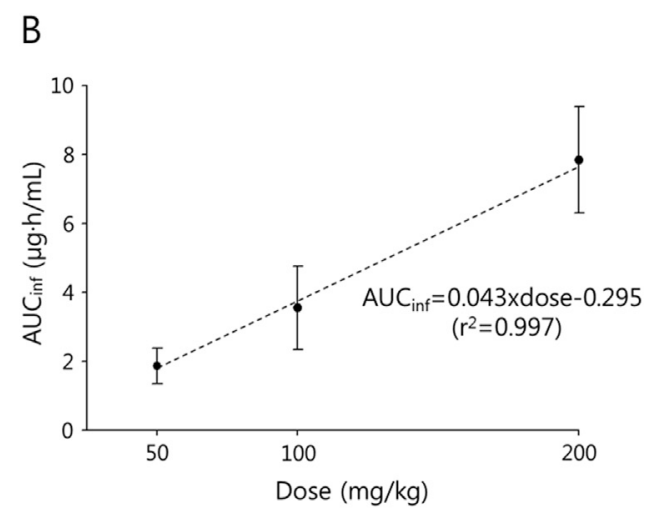

Fig. 2. Panel A: time course of plasma PAN concentrations after oral administration of $200 \mathrm{mg} / \mathrm{kg}$ BPE (16 mg/kg as panduratin A) to rats

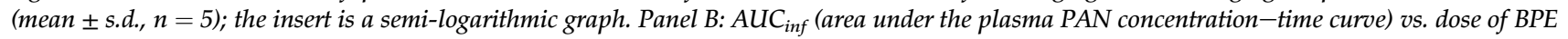
(mean \pm s.d., $n=5)$; the dotted line indicates the result of regression. 
The AUC $\mathrm{Anf}_{\text {in }}$ of PAN vs. the dose of BPE is shown in Fig. 2B. The systemic exposure to PAN was proportional to the dose of $\mathrm{BPE}$ in the range of $50-200 \mathrm{mg} / \mathrm{kg}$, with good linearity $\left(\mathrm{r}^{2}, 0.997\right)$. The terminal half-lives of PAN at 50 and $100 \mathrm{mg} / \mathrm{kg}$ BPE were $8.2 \pm 1.8$ and $9.2 \pm 2.1 \mathrm{~h}$, respectively, indicating that there was no saturable metabolism or excretion of PAN in the dosing range of BPE.

Figure 3 illustrates the time profiles of PAN concentrations in organs (3A: lung, heart, skin, and spleen; 3B: liver, kidney, gums, and brain). The changes in lung and heart PAN levels were similar to that seen in plasma; the gum, liver, spleen, kidney, and brain levels were lower than those in the lung and heart. Interestingly, the maximum skin concentration was recorded $6 \mathrm{~h}$ after those of the other organs and slowly decreased thereafter. The $\mathrm{AUC}_{\mathrm{t}}$ values after $24 \mathrm{~h}$ were in the following order (highest first): skin, lung, heart, gums, liver, spleen, kidney, and brain (Table 1).

\subsection{Pharmacokinetic modeling of plasma and skin $P A N$ levels following oral administration of a BPE}

The plasma PAN concentration-time profile was derived using a two-compartment model including first-order absorption and elimination. As shown in the left panel of Fig. 4, the modeled and measured values around the peak concentration were not similar when the concentration at time $0(0 \mathrm{ng} / \mathrm{mL})$ was included. The plasma PAN concentration increased much more slowly over the first $30 \mathrm{~min}$ than over the next $30 \mathrm{~min}$, and there was a clear latency between PAN administration and its appearance in the circulation. Therefore, a delay term $(\tau)$ was incorporated to shift the curve to the right. The delay was about $0.36 \mathrm{~h}$ and the model fit improved significantly ( $p<0.01$, Fig. 4 , middle).

In the second step, an additional compartment was linked to the central compartment (the skin) (Fig. 1 right). All modeled parameters, except $\mathrm{K}_{\mathrm{a}}$ and $\tau$, showed a good fit with the time course of the skin PAN level (Fig. 4 right). The final model parameters and coefficients of variations are listed in Table 2.

\section{Discussion}

The pretreatment procedure for biological samples, especially tissues, should be well established before beginning a pharmacokinetic study. In this study, both plasma and tissue homogenates were mixed with a 3-fold volume of acetonitrile to precipitate endogenous substances. Recovery is an appropriate parameter to determine whether the pre-treatment is sufficient to quantify a substance. The extraction recovery of PAN in organs in this experiment ranged from 80 to $90 \%$ (data not shown). The mean recovery $(89 \%)$ in liver homogenate, as a representative organ, was slightly better than that $(86 \%)$ in plasma, which indicates that the clean-up procedure was sufficient. Although the matrix effect $(82 \%)$ of liver homogenate was opposite to that $(85 \%)$ of plasma, the difference was negligible. The endogenous substances in both plasma and organs did not affect the quantification of PAN.

In our previous study [14], the pharmacokinetic behaviour of PAN was investigated following oral administration of $5 \mathrm{mg} / \mathrm{kg}$. The biphasic decay after
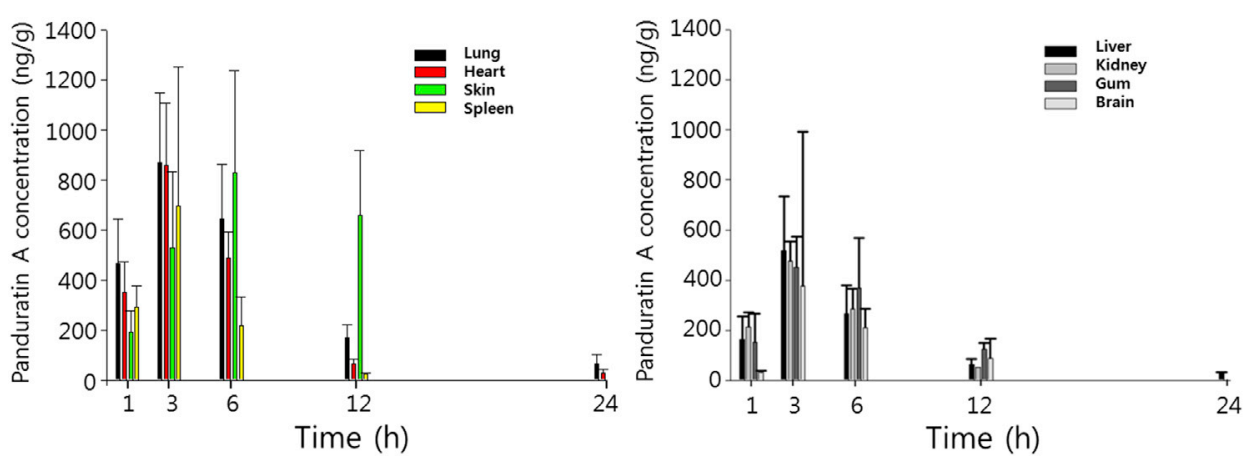

Fig. 3. Concentration-time profiles of PAN for organs after oral administration of $200 \mathrm{mg} / \mathrm{kg}$ BPE (16 $\mathrm{mg} / \mathrm{kg}$ as panduratin A) to rats (mean \pm s.d., $n=5)$.

Table 1. Areas under the PAN organ concentration-time curve values for the heart, lung, liver, spleen, kidney, brain, gums, and skin after oral administration of $200 \mathrm{mg} / \mathrm{kg}$ BPE $(16 \mathrm{mg} / \mathrm{kg}$ as PAN) to rats. Values are means and standard deviations $(n=5)$.

\begin{tabular}{lllllllll}
\hline & Skin & Lung & Heart & Gum & Liver & Spleen & Kidney & Brain \\
\hline $\mathrm{AUC}_{24 \mathrm{~h}}(\mu \mathrm{g} * \mathrm{~h} / \mathrm{g})$ & $14.00 \pm 2.51$ & $7.28 \pm 1.77$ & $5.20 \pm 1.49$ & $4.58 \pm 1.36$ & $4.52 \pm 2.65$ & $3.31 \pm 1.84$ & $2.90 \pm 0.71$ & $2.09 \pm 0.75$ \\
\hline
\end{tabular}



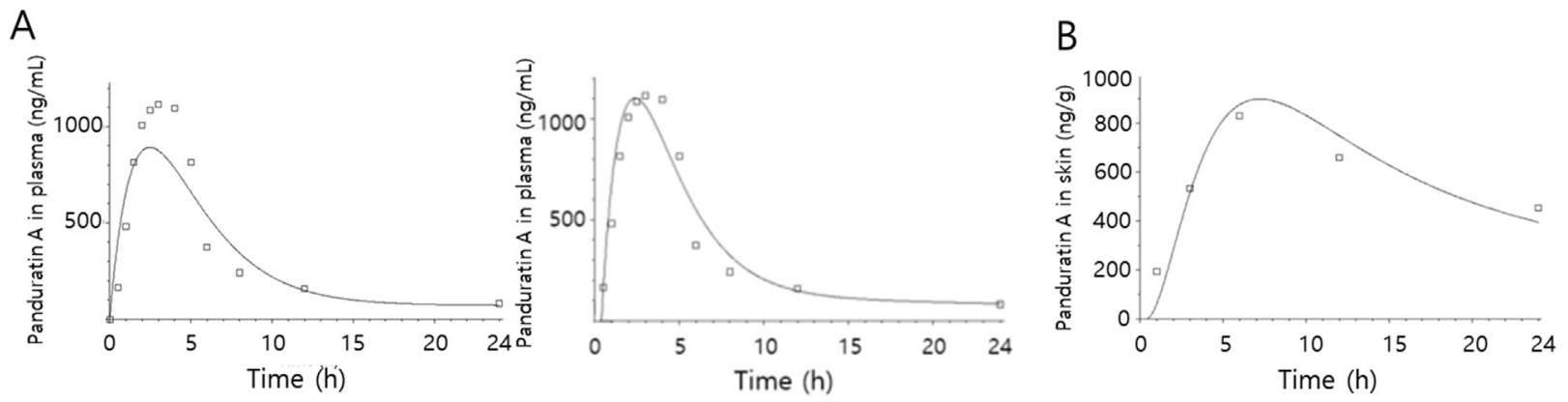

Fig. 4. Panel A: a representative fit of PAN plasma concentration-time profile derived using a two-compartment model including first-order absorption and elimination, without (left) and with (right) of delay term, $\tau$ (see Fig. 1, right); Panel B: Model-fit of panduratin A in skin.

Table 2. Pharmacokinetic parameters of PAN in rat plasma and skin after oral administration of $200 \mathrm{mg} / \mathrm{kg}$ BPE (16 mg/kg as PAN).

\begin{tabular}{llllllllll}
\hline Parameter & $\mathrm{K}_{\mathrm{a}}\left(\mathrm{h}^{-1}\right)$ & $\mathrm{K}_{\mathrm{el}}\left(\mathrm{h}^{-1}\right)$ & $\mathrm{V}_{\mathrm{c}}(\mathrm{mL})$ & $\tau(\mathrm{h})$ & $\mathrm{K}_{\mathrm{cp}}\left(\mathrm{h}^{-1}\right)$ & $\mathrm{K}_{\mathrm{pc}}\left(\mathrm{h}^{-1}\right)$ & $\mathrm{K}_{\mathrm{cs}}\left(\mathrm{h}^{-1}\right)$ & $\mathrm{K}_{\mathrm{sc}}\left(\mathrm{h}^{-1}\right)$ & $\mathrm{V}_{\mathrm{s}}(\mathrm{mL})$ \\
\hline mean & 0.47 & 0.28 & 2.02 & 0.36 & 0.22 & 0.04 & 0.053 & 0.126 & 0.34 \\
$\mathrm{CV}(\%)$ & 14.9 & 3.6 & 19.2 & 11.1 & 18.2 & 25.0 & 37.7 & 23.8 & 38.3 \\
\hline
\end{tabular}

the plasma peak was similar to that observed in this study. However, the terminal half-life $(3.6 \mathrm{~h})$ was remarkably prolonged (2.4-fold; $p<0.01$ ), and clearance was decreased by $37 \%$ when PAN was given as an ingredient in a BPE, probably indicating that other substances (composing $>80 \%$ of the extract) may hinder PAN metabolism and/or excretion. An increase of AUC normalized to the dose $(0.28-0.44 \mathrm{~kg} \mathrm{~h} / \mathrm{L})$ may also reflect this possibility.

The change of clearance seemed to be much smaller than that of half-life. Since pharmacokinetic parameters are mostly calculated from the time course of plasma concentrations, the change of clearance is mainly dependent on the schedule of blood sampling, dose, and quantification sensitivity, and the half-life can be much more variable compared to the other parameters. PAN was previously monitored for up to $12 \mathrm{~h}$ due to early disappearance from the systemic circulation, which seems insufficient for accurate measurement of the half-life. Therefore, clearance is more reliable than half-life when comparing pharmacokinetic changes of PAN following oral administration of PAN and BPE.

Systemic exposure to PAN increased in a dosedependent manner after oral administration of BPE at doses of $50-200 \mathrm{mg} / \mathrm{kg}$ (Fig. 2B). We could predict the tissue distribution of PAN down to $50 \mathrm{mg} / \mathrm{kg}$ due to kinetic homogeneity. To the best of our knowledge, this is the first study to report tissue concentrations of PAN, including in the skin and gums. Although these two organs are not usually examined, we were interested in the relationship between the PAN concentrations therein and its pharmacological activity [6-8,11]. Gum tissue samples were collected from the outer mandibular regions, and the PAN levels were similar to those in the liver samples. PAN activity against LPS-induced periodontitis is of interest $[7,8]$, where few pharmacologically active substances have been derived from natural products. PAN may also protect against gingival inflammation.

There have been many previous reports of the skin distribution of active substances following oral administration, but fewer on the distribution in major organs such as the liver, heart, lung, and brain. Okawara et al. prepared $\beta$-cyclodextrin complexes of diosgenin, and assessed the reduction of skin thickness in ovariectomized mice and distribution of diosgenin in the skin [17]. The complexes improved the oral bioavailability of diosgenin by 8fold compared to diosgenin alone, and skin exposure was enhanced by 10 -fold. In a rat study of the intracellular lipids of the stratum corneum, $16 \%$ of the tritium-labelled ceramide that was absorbed orally remained in the dermis [18]. Substances reaching the skin can improve its function. In addition, exposure of the skin at the dermal interstitium to doxycycline was studied using a microdialysis technique, following daily oral administration for 14 days in healthy volunteers [19]. The $\mathrm{AUC}_{24 \mathrm{~h}}$ values of doxycycline in the skin was $30 \%$ and $40 \%$ of that in the plasma on days 1 and 14, respectively. Considerable accumulation of doxycycline in the skin was clearly demonstrated; this accumulation may contribute to its efficacy in rosacea.

In this study, the PAN level was much higher in skin than in the major organs; for example, it was 
A
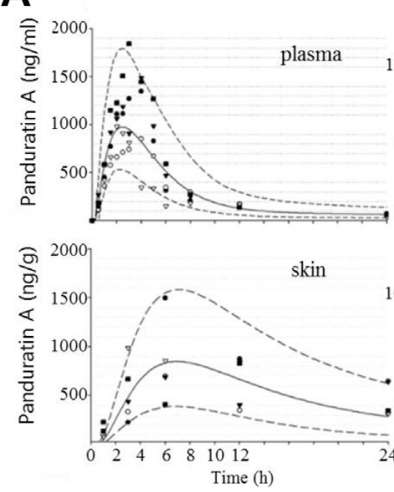
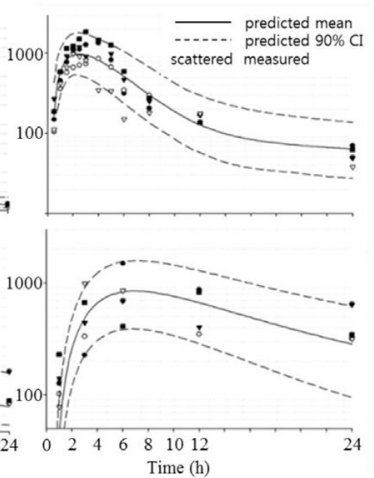

B

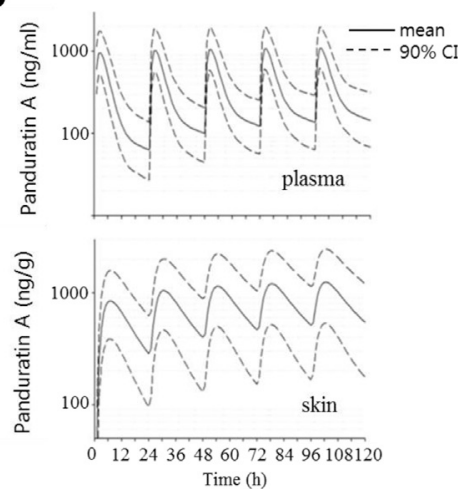

Fig. 5. Panel A: Visual predictive check of the pharmacokinetic model of plasma (top) and skin PAN levels (bottom). The solid lines indicate the 50th percentile, and the dashed lines indicate the 5th and 95th percentiles; Panel B: Simulated time courses of plasma (top) and skin (bottom) PAN levels after oral administrations of $200 \mathrm{mg} / \mathrm{kg}$ of BPE $(16 \mathrm{mg} / \mathrm{kg}$ as PAN) to rats. The solid and dashed lines are the mean and 90th percentile values, respectively.

about two-fold higher than the concentration in lung (the most exposed major tissue), perhaps explaining the good skin-moisturizing and UV irradiation-protective effects of PAN [10,11]. Therefore, we used model-dependent analysis to further investigate skin exposure to PAN. The quality of the model was assessed using a visual predictive check, as shown in Fig. 5 (Panel A). Monte Carlo simulation $(1,000)$ was performed to obtain $90 \%$ confidence intervals (CIs). Few data points lay outside of the CIs, indicating that the model predictions of plasma and skin PAN were reliable.

Using the pharmacokinetic parameter data derived by varying a single dose, stochastic simulation can predict plasma levels when different doses are administered at various time points. Panel $B$ in Fig. 5 shows the results of simulations of plasma and skin PAN levels after five BPE doses of $200 \mathrm{mg} /$ $\mathrm{kg}$ in rats. The time course of the skin PAN level can be correlated with data on its moisturizing activity or protective action, to enhance our understanding of the relationship between PAN pharmacokinetics and pharmacodynamics.

In summary, to the best of our knowledge, this study is the first to explore the time course of PAN levels in rat plasma and major organs (including the gums and skin) after oral administration of BPE. The PAN level was highest in the skin, at twofold that in the lungs; the level in the gums was $33 \%$ of that in the skin. Our results help to explain the pharmacological activities of PAN in the skin and gums. The pharmacokinetic model provided quantitative data on plasma and skin PAN levels, which are of fundamental importance when evaluating the efficacy of PAN.

\section{Acknowledgments}

This work was supported by the National Research Foundation of Korea (NRF) grant funded by the Korea government (MSIP) (No. 2015R1A5A1008958).

\section{References}

[1] Chahyadi A, Hartati R, Wirasutisna KR. Elfahmi. Boesenbergia Pandurata Roxb., an Indonesian medicinal plant: phytochemistry, biological activity, plant biotechnology. Proc Chem 2014;13:13-37.

[2] Rukayadi Y, Lee K, Han S, Yong D, Hwang JK. In vitro activities of panduratin A against clinical Staphylococcus strains. Antimicrob Agents Chemother 2009;53:4529-32.

[3] Choi Y, Kim MS, Hwang JK. Inhibitory effects of panduratin A on allergy-related mediator production in rat basophilic leukemia mast cells. Inflammation 2012;35:1904-15.

[4] Sohn JH, Han KL, Lee SH, Hwang JK. Protective effects of panduratin A against oxidative damage of tert-butylhydroperoxide in human HepG2 cells. Biol Pharm Bull 2005;28: 1083-6.

[5] Yun JM, Kwon H, Hwang JK. In vitro anti-inflammatory activity of panduratin A isolated from Kaempferia pandurata in RAW264.7 cells. Planta Med 2003;69:1102-8.

[6] Tewtrakul S, Subhadhirasakul S, Karalai C, Ponglimanont C, Cheenpracha S. Anti-inflammatory effects of compounds from Kaempferia parviflora and Boesenbergia pandurata. Food Chem 2009;115:534-8.

[7] Kim H, Kim C, Kim D, Chung H, Hwang J. Inhibitory effects of Boesenbergia pandurata on age-related periodontal inflammation and alveolar bone loss in Fischer 344 rats. J Microbiol Biotechnol 2018;28:357-66.

[8] Kim H, Kim C, Yanti Kook KE, Choi S, Kang W, Hwang JK Inhibitory effects of standardized Boesenbergia pandurate extract and its active compound panduratin A on lipopolysaccharide-induced periodontal inflammation and alveolar bone loss in rats. J Med Food 2018;21:961-70.

[9] Yanti Oh HI, Anggakusuma, Hwang JK. Effects of panduratin A isolated from Kaempferia pandurata Roxb. on the expression of matrix metalloproteinase- 9 by porphyromonas gingivalis supernatant-induced KB cells. Biol Pharm Bull 2009;32:110-5. 
[10] Shim JS, Kwon YY, Han YS, Hwang JK. Inhibitory effect of panduratin A on UV-induced activation of mitogen-activated protein kinases (MAPKs) in dermal fibroblast cells. Planta Med 2008;74:1446-50.

[11] Kim DU, Chung HC, Kim C, Hwang JK. Oral intake of Boesenbergia pandurata extract improves skin hydration, gloss, and wrinkling: a randomized, double-blind, and placebocontrolled study. J Cosmet Dermatol 2017;16:512-9.

[12] Woo SW, Rhim DB, Kim C, Hwang JK. Effect of standardized Boesenbergia pandurata extract and its active compound panduratin A on skin hydration and barrier function in human epidermal keratinocytes. Prev Nutr Food Sci 2015;20:15-21.

[13] Kim DY, Kim MS, Sa BK, Kim MB, Hwang JK. Boesenbergia pandurata attenuates diet-induced obesity by activating AMP-activated protein kinase and regulating lipid metabolism. Int J Mol Sci 2012;13:994-1005.

[14] Kim M, Choi S, Noh K, Kim C, Kim E, Hwang JK, et al. Determination of panduratin A in rat plasma by HPLC-MS/ MS and its application to a pharmacokinetic study. J Pharmaceut Biomed Anal 2017;137:151-4.
[15] Kim TH, Shin S, Jeong SW, Lee JB, Shin BS. Physiologically relevant in vitro-in vivo correlation (IVIVC) approach for sildenafil with site-dependent dissolution. Pharmaceutics 2019;11:251.

[16] Kim M, Son H, Noh K, Kim E, Shin BS, Kang W. Effects of verapamil and diltiazem on the pharmacokinetics and pharmacodynamics of rivaroxaban. Pharmaceutics 2019;11: 133.

[17] Okawara M, Tokudome $Y$, Todo H, Sugibayashi K Hashimoto F. Enhancement of diosgenin distribution in the skin by cyclodextrin complexation following oral administration. Biol Pharm Bull 2013;36:36-40.

[18] Ueda O, Hasegawa M, Kitamura S. Distribution in skin of ceramide after oral administration to rats. Drug Metab Pharmacokinet 2009;24:180-4.

[19] Pal A, Matzneller P, Gautam A, Österreicher Z, Wulkersdorfer B, Reiter $B$, et al. Target site pharmacokinetics of doxycycline for rosacea in healthy volunteers is independent of the food effect. $\mathrm{Br}$ J Clin Pharmacol 2018;84:2625-33. 